\title{
Una revisión contemporánea a la doctrina de la distinción de poderes ${ }^{1}$
}

\section{A contemporary revision of the doctrine of the distinction of powers}

Recibido: 15 de diciembre de 2015 - Revisado: 29 de abril de 2016 - Aceptado: 23 de junio de 2016.

\author{
Alejandro Gómez Velásquez ${ }^{2}$ \\ Mario Montoya Brand ${ }^{3}$
}

\begin{abstract}
Resumen
La distinción de poderes es una doctrina típicamente moderna. Con ella, se suele hacer referencia conjunta a los principios de división del poder, separación entre poderes y frenos y contrapesos entre los órganos del poder político. Esta doctrina guarda vigencia en nuestros días, en tanto, se suele partir de ella para estructurar los Estados desde la modernidad hasta nuestros días. Sin embargo, a raíz de los retos que enfrenta el Estado contemporáneo, dicha doctrina se encuentra en entredicho, por lo que han aparecido defensores y detractores contemporáneos de la misma. En este orden de ideas, el presente documento ofrece algunas precisiones sobre los orígenes, alcances y contenidos de la distinción de poderes al acudir a sus orígenes doctrinales.
\end{abstract}

\section{Palabras clave}

División del poder, separación entre poderes, frenos y contrapesos, Estado, instituciones, balance.

\begin{abstract}
The distinction of powers is a typically modern doctrine. With it, reference is often made to the principles of division of power, separation of powers and checks and balances between the organs of political power. This doctrine is valid in our days, while it is usually based on it the structuring of states from modernity to our days. However, as a result of the challenges facing the contemporary State, this doctrine is in question, so have appeared defenders and contemporary detractors of the same. In this vein, this document offers some clarifications on the origins, scope and content of the distinction of powers by referring to its doctrinal origins.
\end{abstract}

\section{Keywords}

Division of powers, separation between powers, checks and balances, State, institutions, balance.

\footnotetext{
1 Este artículo forma parte de los resultados parciales del proyecto de investigación: "La 'colaboración armónica' interorgánica en Colombia como presupuesto para el cumplimiento de los fines del Estado. Construcción de un marco conceptual y aplicación a un estudio de caso", desarrollado por el Grupo Derecho y Poder de la Escuela de Derecho de la Universidad EAFIT de Medellín, Colombia, con financiación interna.

2 Abogado, politólogo y especialista en Derecho Público de la Universidad EAFIT. Magíster en Derecho Constitucional del CEPC y LL.M en Estudios Jurídicos Internacionales de American University, Washington D.C. Profesor e investigador de la Escuela de Derecho, Universidad EAFIT, Medellín, Colombia.

Correo electrónico: agomezv1@eafit. edu.co

${ }^{3}$ Abogado y magíster en Ciencias Políticas de la Universidad de Antioquia. Doctor en Derecho Público de la Universidad Autónoma de Barcelona. Profesor e investigador de la Universidad EAFIT, Medellín, Colombia. Correo electrónico: mbrand@eafit. edu.cqo

Para citar este artículo use: Gómez, A., \& Montoya, M. (2017). Una revisión contemporánea a la doctrina de la distinción de poderes. Civilizar Ciencias Sociales y Humanas, 17(32), 49-66. Doi: 10.22518/16578953.817
} 


\section{Introducción}

La historia de las ideas políticas ha transcurrido en torno a la adscripción de valores como fines esperados del ejercicio del poder político, sin embargo, con el reciente resurgimiento de los estudios institucionalistas se ha puesto de presente el que, igual de relevante que la discusión por los valores y fines, se encuentran los debates sobre las estructuras institucionales y procesales, que son necesarias para ser logrados aquellos en la práctica y también para que puedan conciliarse entre ellos mismos. En este orden de ideas, ha sido una constante en los estudios acerca de la política, del Estado y del Derecho, desde la antigüedad hasta nuestros días, la pregunta por la debida articulación entre las instituciones en el sistema político, y también por cómo esta puede servir para materializar algunos fines y valores políticos. De estas reflexiones, llama particularmente la atención el hecho de que desde la modernidad hasta hoy, la fórmula que brinda la doctrina de la distinción de poderes ha sido la más significativa, tanto en términos teóricos como prácticos, para condicionar la estructura de los Estados. De acuerdo con Carré de Malberg (1998), una excepción notable es el caso de Georg Jellinek (2002), para quien esta doctrina ha tenido un papel secundario en la práctica (p. 786).

En la actualidad son grandes los retos que enfrenta la institucionalidad estatal. Nuevas expectativas, funciones, arreglos institucionales y retos de gobernabilidad, entre otros, evidencian una coyuntura donde son presentadas como muy convenientes, trascendentales trasformaciones del andamiaje estatal que le permitan a cada Estado responder a esos retos. Así las cosas, preguntarse hoy por la vigencia, el contenido y la conveniencia de una doctrina como la de la distinción de poderes, resulta de la mayor pertinencia y novedad.

Sin embargo, para disponerse a dicha empresa, conviene afirmar desde ahora que el uso contemporáneo que suele hacerse de la distinción de poderes como doctrina ha sido ambiguo, al existir una importante confusión en la definición y uso de los términos, como lo han advertido estudios recientes sobre la materia (Vile, 1998; Waldron, 2013). Y es que la separación de poderes ha sido combinada con otras ideas políticas como la del gobierno mixto, la idea de equilibrio y el concepto de checks and balances; y tal vez debido a ello, suelen utilizarse indistintamente en la bibliografía especializada los términos de separación, división y equilibrio de poderes. El uso discorde de los términos igualmente se hizo presente en el tratamiento del tema bajo el desarrollo de la Teoría del Estado (Carré de Malberg, 1998; Heller, 1997; Jellinek, 2002; Kelsen, 1975; Schmitt, 2011). Por lo tanto, con el objeto de distinguir las ideas y principios políticos que suelen asociarse y muchas veces confundirse, en el presente texto se utiliza el término "distinción de poderes" (Schmitt, 2011, p. 248), para referirnos a la noción más genérica y a partir de allí discernir las variadas ideas que contemporáneamente suelen confluir en ella.

Así las cosas, el presente artículo se propone una revisión de las obras de autores modernos y contemporáneos sobre la distinción de poderes, desde una perspectiva analítica, al buscar discernir, ordenar y clarificar las premisas que pueden ubicarse en sus orígenes; determinar cuáles perviven hoy $\mathrm{y}$, posteriormente, presentar un estado del arte sobre algunos de los argumentos que se han utilizado recientemente para sostener o criticar la vigencia de esta doctrina como fundante de la estructura de los Estados contemporáneos. Metodológicamente se ejecuta mediante una investigación documental.

Para estos efectos, en un primer apartado se recurrirá a identificar los orígenes de la doctrina de la distinción de poderes. Con tal objetivo se hará un rastreo de la literatura que ordinariamente suele identificarse como fuente de esta doctrina, en especial, en las obras de 
John Locke, Montesquieu y James Madison. Por esta senda se busca establecer si en las obras de estos autores clásicos se puede identificar una misma noción de distinción de poderes o si, por el contrario, sus trabajos desarrollan premisas que, si bien pueden distinguirse, a su vez se relacionan con la doctrina mencionada.

En un segundo apartado, se hará un rastreo sobre los principales autores y argumentos que con frecuencia son recurridos para sostener la vigencia y conveniencia de esta doctrina en relación con el Estado contemporáneo; en función de tal objetivo se busca relacionar y sistematizar los principales argumentos que se identifiquen. Luego, en un tercer apartado, se presentarán los principales argumentos que en el mismo contexto suelen esgrimirse en contra de la distinción de poderes, también con el objeto de sistematizarlos y caracterizarlos. Por último, se presentarán algunas conclusiones y balances que pueden colegirse del ejercicio realizado.

\section{Las premisas clásicas de la distinción de poderes}

Desde la antigüedad, pueden identificarse pensadores políticos que se aplicaron a denominar y clasificar las diversas manifestaciones del poder político. Un ejemplo paradigmático de ello lo constituye la distinción realizada por Aristóteles (2001, 1287a) en La Política entre los tres segmentos de las funciones estatales: las deliberaciones sobre asuntos de interés común, la organización de cargos o magistraturas y la función judicial. Sin embargo, en estos ejercicios iniciales no es posible identificar aun la que se tendría luego como la esencia de la doctrina de la distinción de poderes, ya que aquella identificación de funciones públicas se dirigía menos a buscar un poder político limitado a través de su estructura que a sugerir su buen funcionamiento a partir de la metáfora organicista (Rubin, 2005, p. 39). Para Loewenstein (1976), incluso, la diferencia esencial entre la distinción de poderes elaborada por Aristóteles y la moderna radica en que en la Grecia antigua no existía la representación política que es connatural a la distinción de poderes moderna (p. 58).

Esa labor intelectual de distinguir las funciones se mantuvoen los pensadores políticos durante los siglos siguientes e incluso durante el Medioevo. En este sentido, pensadores como Harrington (1999), posteriormente Polibio (2008) y Padua (2009), continuaron teorizando sobre la conveniencia del "gobierno mixto" para satisfacer los estándares de lo que se tenía como un buen gobierno. Ahora bien, desde un punto fáctico, ya desde la antigüedad hasta la Alta Edad Media, en especial para ese entonces en Inglaterra, la paulatina erosión del poder del monarca que condujo a la imposición de límites a su imperium, en especial por parte del Parlamento, había dado lugar a la idea de la distinción de funciones en el ejercicio del poder político.

Ya en tiempos modernos, es John Locke (1959) quien logra teorizar con mayor suficiencia sobre la conveniencia de la distinción del poder como estrategia para el control del poder. En su Segundo Tratado sobre el Gobierno Civil, escrito inmediatamente después de concluir la revolución en 1688, el pensador inglés parte de distinguir entre cuatro potestades atribuibles a la organización estatal: el poder legislativo, el ejecutivo, el federativo y la prerrogativa (pp. $106-116)$.

Dentro de sus principales argumentos dirigidos a justificar la distinción a través de la división funcional del poder se encuentran, por un lado, un argumento de eficiencia; y por otro, uno de conveniencia. En relación con el primero, se sostiene que los poderes legislativos y ejecutivos deberían distinguirse, en tanto las leyes requieren un corto tiempo para ser promulgadas, pero necesitan de "ejecución perpetua" (p. 114); es decir, de un poder ejecutivo permanente. En este sentido, por la naturaleza representativa y colegiada del poder legislativo, este se torna lento, engorroso 
e ineficiente para la debida ejecución de las leyes, por lo cual se justifica el que se distinga de forma permanente entre ambas funciones.

Por su parte, frente al argumento de conveniencia, señala Locke (1959), la teoría de la división de poderes aparece como atractiva para evitar la opresión por parte de un gobierno tiránico al asegurar que quien crea las leyes no sea quien participe en su ejecución o incluso en el juzgamiento con base en ellas. En palabras del autor:

$[P]$ uede ser una tentación demasiado grande para la fragilidad humana [...] el que las mismas personas que tienen la facultad de hacer leyes tengan también en sus manos el poder de ejecutarlas, con lo cual pueden eximirse por sí mismas de la obediencia de las leyes que dictan, y acomodar la ley, tanto en su elaboración como en la ejecución, a su propia ventaja particular, y por ello venir a tener un interés distinto al del resto de la comunidad y contrario al fin de la sociedad y del gobierno (p. 114).

Si bien Locke (1959) en su obra parece sugerir una deseable distinción entre estas funciones del poder político, en especial, respecto a la potestad legislativa y ejecutiva, ello no implica que para el autor inglés dichos poderes necesariamente debieran estar separados y por ende radicados en distintas personas $\mathrm{u}$ órganos, situación que se explicita con la posible participación de la persona que represente el órgano ejecutivo en las labores legislativas (p. 118). Por ello, puede afirmarse que en la obra de Locke no se reprueba el hecho que en la práctica y en la teoría dichas potestades puedan acumularse en una misma persona o institución, o incluso el que se señale abiertamente la prevalencia del poder legislativo sobre los demás poderes divididos.

Por otro lado, para el pensador inglés, es no solo posible sino deseable que exista subordinación de un poder sobre los demás, al ser en este caso la supremacía propia del poder legislativo sobre los demás (p. 119). Esta concepción ha dado lugar a dos corrientes muy diferentes defensoras de la jerarquía entre órganos, las cuales son críticas con la idea de un equilibrio entre los poderes del Estado: de un lado, la de aquellos que temen que la igualdad entre poderes conduzca a la anarquía dentro del Estado (Carré de Malberg, 1998, p. 751); y del otro, la perspectiva kelseniana, según la cual, es de la esencia del Derecho -y por ende del Estado en su doctrina- la subordinación entre poderes, por lo cual, la igualdad entre poderes, o mejor, entre funciones que producen Derecho, es imposible (Kelsen, 1975, p. 334).

Muy influenciada por los sucesos y escritos ingleses de la época, en especial por la obra de Bolingbroke (1997) y Locke (1959), se encuentra posteriormente la obra de Charles Louis de Secondat, Baron de Montesquieu. Para acercarnos a su contribución en la materia, valga destacar el punto de partida de la obra El espiritu de las leyes (1977) y en especial del capítulo titulado "La Constitución de Inglaterra", el cual queda en evidencia por la contundencia de sus palabras:

Es una experiencia eterna que todo hombre que tiene poder se ve llevado a abusar del mismo; va hacia adelante hasta que tropieza con límite [...] Para que no pueda abusar del poder, es preciso que, por la disposición de las cosas, el poder detenga al poder (p. 104).

Una vez identificado el presupuesto antropológico para el autor, se colige en su obra que la persona o el cuerpo político que es dueño de todos los poderes a la vez, posee una potestad ilimitada, puesto que no existe, fuera de él, ninguna potestad que pueda limitar la suya. Por lo tanto, el peligro de toda potestad sin límites es la posible opresión de los ciudadanos, los cuales frente a tal potestad quedan expuestos a la arbitrariedad. Bajo estas premisas, y con el fin de evitar este peligro, es indispensable, en el principio y en la base de toda organización de los poderes, hallar una combinación que, al multiplicar las autoridades públicas y al repartir 
entre ellos los diversos atributos de la soberanía, tenga por objeto limitar respectivamente la potestad de cada una de ellas por la potestad de las autoridades vecinas, de tal modo que ninguna pueda llegar jamás a una potestad excesiva.

En este punto, es que el autor francés plantea con contundencia que la solución a este problema consiste en separar las que a su juicio deben ser las funciones estatales, a saber, la legislativa, la ejecutiva y la judicial, y así, entregarlas respectivamente a tres órganos, distintos y diferenciados. Por lo tanto, y sin utilizar textualmente los términos de separación de poderes en su obra, se inmortaliza por parte del pensador francés el principio, según el cual, "todo estaría perdido, si el mismo hombre o el mismo cuerpo ejerciera esos tres poderes: el de hacer las leyes, el de ejecutar y el de juzgar" (Montesquieu, 1977, p. 104).

Como desarrollo de este principio, Montesquieu (1977) señala qué razones justifican la separación entre los tres poderes mencionados. Así, indica el autor que es preciso que los poderes legislativo y ejecutivo estén separados por las siguientes dos razones: (i) la noción de ley que sostiene el autor basa su justicia en el carácter abstracto y general, y, por tanto, en el estar desprovista de intereses particulares o contingentes (p. 59). Por lo tanto, cuando se comparte la función de su creación y la ejecución de las leyes, es muy probable que estas se creen y/o se ejecuten siguiendo intereses precisos que afectan las garantías de libertad de los individuos; y (ii) si ambos poderes estuvieran reunidos, podría suceder que la autoridad encargada de ejecutar no se consideraría obligada por las leyes vigentes, puesto que podría abrogarlas y modificarlas a su antojo, con lo cual se trastocaría la garantía del régimen de la legalidad.

Por razones asimilables, Montesquieu (1977) sostiene que es necesario también separar las potestades legislativa y judicial ( $p$.
105). De no ser ello así, el juez, al ser al mismo tiempo legislador, podría él también, bien separarse de la ley o bien cambiar esta según su capricho en el instante mismo en que tuviera que aplicarla. Entre las manos de semejante juez, declara el autor, el poder sobre la vida y la libertad de los ciudadanos sería arbitrario. Finalmente, justifica que el poder judicial esté separado del ejecutivo, al señalar que el agente ejecutivo que además sería juez, podría, en el curso de la ejecución, desnaturalizar el alcance de la aplicación de las leyes mediante juicios tendenciosos e inocuos, según tuviera interés en que dicha ejecución se hiciera en determinado sentido.

Todo este razonamiento de Montesquieu conduce a la idea principal, según la cual, se trata de asegurar la libertad de los ciudadanos mediante la separación de poderes, pero proporcionándoles la garantía de que cada uno de estos se ejercerá legalmente. De lo dicho se colige, como lo afirma Carré de Malberg (1998), interpretando al señor de la Brède, que únicamente la separación de los poderes puede proporcionar a los gobernados una serie de garantías y una eficaz protección contra la opresión (p. 746). Si bien existe cierto consenso acerca de que la separación de poderes busca garantizar la libertad, algunos han considerado que no ha sido del todo claro si con ella se busca garantizar la libertad de los ciudadanos o su seguridad (Hauriou, 1971, p. 236).

Luego, será en las discusiones sobre la Constitución de los Estados Unidos de 1787 donde se retome la distinción de poderes y se replanteen algunos asuntos esenciales. Madison, Hamilton y Jay (2010), en El Federalista, serán quienes directamente abordarán el asunto. Estos autores parten de la ya célebre premisa de Montesquieu, según la cual no habrá libertad donde no exista separación de poderes ( $p$. 199), sin embargo, a renglón seguido señala que dicha premisa no implica el que no pueda existir una "intervención parcial" de los actos de un poder sobre los de otro. En este sentido, 
señalan los autores que si bien el poder puede estar separado, nada obsta para que alguno de ellos predomine sobre los demás, tal y como la teoría y la experiencia lo han demostrado. Por lo tanto, dichos límites no deberán solo constar en el texto constitucional para evitar las usurpaciones de poder por parte de otro u otros, sino que deberá idearse la estructura interior del gobierno de tal modo que sean sus distintas partes constituyentes, por sus relaciones mutuas, los medios de conservarse unas a otras en su sitio, en palabras de Madison, Hamilton y Jay (2010):

Pero la mayor seguridad contra la concentración gradual de los diversos poderes en un solo departamento reside en dotar a los que administran cada departamento de los medios constitucionales y los móviles personales necesarios para resistir invasiones de los demás. [...] la ambición debe ponerse en juego para contrarrestar a la ambición [...] Al organizar un gobierno que ha de ser administrado por hombres para los hombres, la gran diferencia estriba en esto: primeramente hay que capacitarlo para mandar sobre los gobernados; $y$ luego obligarlo a que se regule a sí mismo (p. 220).

Un año después de ser publicado este escrito, se inmortalizará la doctrina de la separación de poderes en la cultura política de occidente a partir de lo dispuesto por la Declaración de los Derechos del Hombre y del Ciudadano de 1789, que dispuso en su artículo 16: "Una sociedad en la que la garantía de los derechos no está asegurada, ni la separación de poderes determinada, no tiene Constitución".

\section{Los principios de división, separación $y$ equilibrio de poderes}

Sin embargo, del recuento hecho de los orígenes de la doctrina de la distinción de poderes puede señalarse con Vile (1998), pues esta "representa un área del pensamiento político en la cual ha existido una extraordinaria confusión en la definición de los términos" (p. 2). La principal razón de ello es que como pudo evidenciarse, entre los principales autores clásicos a los que se les atribuye el origen de la doctrina, se hace mención de teorías que si bien pueden estar relacionadas son diferentes entre sí y no sostienen una idea uniforme sobre lo que implica la distinción de poderes (Waldron, 2013, p. 438). En este sentido, pueden identificarse en las obras de los tres autores referidos, al menos tres principios distinguibles que subyacen a la mencionada doctrina.

En primer lugar, encontramos el principio de división del poder (Guastini, 2000 , p. 59). Este principio aboga por que el ejercicio del poder político del Estado debe dividirse en distintas funciones o competencias distinguibles entre sí. Si bien los criterios para la división del poder, sus alcances e incluso sus denominaciones han variado entre los autores posteriores a los clásicos, y persistido hasta nuestros días, el núcleo de este principio se basa en la idea de promover un gobierno mixto donde el ejercicio del poder se divida funcionalmente, con lo cual se evidenciaría el carácter instrumental del mismo. Este principio, en rigor, no proscribe la posibilidad que las funciones del Estado puedan estar concentradas en una misma persona $u$ órgano, que uno de ellos pueda prevalecer sobre los demás, o que el Estado pueda prestar funciones diferentes a las tres generalmente aceptadas, estas situaciones serán objeto de principios diferentes, como se verá a continuación.

Si bien este propósito, como pudo señalarse antes, tiene sus raíces en la antigüedad (Vile, 1998, p. 3), al respecto resulta de gran novedad la obra de John Locke. Aunque su propuesta particular de división del poder no gozó de plena aceptación en la construcción de los Estados modernos, al prevalecer la canónica idea de la tridivisión de poderes, el autor inglés sí fue el precursor en teorizar, a partir de los sucesos de la Glorius Revolution, sobre un conjunto de reglas funcionales que propusieran la conveniencia de emprender la operación 
de seccionar el todopoderoso Leviatán en diferentes segmentos funcionales, al quebrar la unidad propia del poder del Estado absolutista y buscar su limitación (Loewenstein, 1976 p. 60).

En segundo lugar, encontramos el principio de separación entre poderes. Este principio se dirige en contra de la concentración del poder en una persona, grupo u órgano. Por lo tanto, este principio aboga por que las funciones en las que se ha dividido el poder, deberán ser ejercidas por personas, órganos o ramas separadas, distinguibles y sin solapamientos entre ellas. El fundamento de este principio radica en la separación entre poderes como una estrategia para las eventuales conductas opresivas por parte de un poder político concentrado $\mathrm{y}$, por ende, como un instrumento para la protección y defensa de la libertad política de los ciudadanos.

En este sentido, dicho principio promulga la idea de un gobierno balanceado (balanced government) a partir de una precisa y estricta separación no solo funcional, sino también física entre los órganos y estamentos que ejerzan el poder. En otras palabras, al recurrir a una visión mecanicista, muy propia del pensamiento newtoniano (Bellamy, 2007, p. 209), a partir de una separación estricta entre los órganos funcionales del poder, señala el principio que se logrará un control y límite entre ellos, al evitar su concentración y con ello sus posibles excesos. En este sentido, las precisas competencias de cada poder público deberán estar expresas y taxativamente establecidas en los textos constitucionales, y en virtud del principio de legalidad, cualquier actuación por fuera de ellas podrá ser declarada como inválida e ilegal por exceso en la competencia atribuida (ultra vires). Así las cosas, el principio de la separación de poderes proscribe no solo la prevalencia, sino también la injerencia de cualquier poder sobre otro, ya que lo que está en juego son los controles, es decir, la garantía de un poder limitado por sus mismos compartimentos.
Como el claro fundador de este principio encontramos, sin lugar a dudas, a Montesquieu, quien como ya se señaló, defendió en su obra la conveniencia no solo de un poder dividido en las canónicas funciones: legislativa, ejecutiva y judicial, sino también separado estrictamente entre quienes lo ejercen, con el fin de autolimitarse y así crear un balance que evite el exceso y la opresión frente a los ciudadanos (Waldron, 2013, p. 455).

En tercer y último lugar, encontramos el principio de frenos y contrapesos (checks and balances) como componente de la doctrina de la separación de poderes. Este principio parte de reconocer la conveniencia de los principios de división y separación de poderes, sin embargo, complementa la estrategia para lograr ese gobierno equilibrado, al señalar que por la dinámica misma del poder, este no se logrará únicamente a partir de la separación estricta entre los poderes, sino que es necesario que estos concurran ordinariamente en las competencias o funciones de otro, lo que da lugar a que un poder controle o vete las acciones de otro. Dicho de otro modo, si bien se parte de la conveniencia de un poder dividido y separado funcionalmente, dicha separación de funciones será flexible, en tanto el balance que se pretende entre los poderes públicos es un resultado que se realiza y se reafirma de manera constante, mediante el control político, la intervención de unos órganos en las tareas correspondientes a otros y las relaciones de colaboración entre las distintas ramas del poder público en el ejercicio de sus competencias (Gargarella, 2003, p. 11).

Este principio puede rastrearse hasta la obra de El Federalista, en especial, en los escritos de James Madison, quien como se explicó en este mismo texto, justificó la necesidad de complementar los mecanismos tendientes al equilibrio y auto control del poder público no solo a partir de una separación precisa de funciones y titulares de las mismas, sino también a partir de la concurrencia de algunos de estos poderes en el desarrollo de funciones 
comunes. En gran parte, este principio se vio desarrollado en la Constitución de los Estados Unidos de 1789 al establecer sendos controles interorgánicos y poderes de veto, que actúan como frenos y contrapesos entre los poderes públicos para evitar la prevalencia de alguna facción o poder político sobre los demás. En las palabras de Richard E. Neustadt (1990), dicho principio puede ser definido con la fórmula separated institutions sharing powers (p. 29).

A manera de síntesis, puede afirmarse que la distinción de poderes es una doctrina propia del pensamiento político moderno, basada en una perspectiva instrumental y funcional del poder político. El ethos de esta doctrina puede identificarse en la idea de estructurar el ejercicio del poder político de tal forma que este se limite y/o se controle internamente para evitar su concentración y abuso hacia los ciudadanos, de allí su estrecha relación con el liberalismo y particularmente con la libertad política. Sin embargo, al estudiar sistemática y analíticamente dichos orígenes modernos, pueden identificarse en las obras de sus principales representantes que con la doctrina de la distinción de poderes se suele hacer mención de tres diferentes principios que a pesar de ser complementarios en sus postulados, orígenes y autores representativos son distinguibles, a saber:

Tabla 1.

Los principios de la Distinción de Poderes

\begin{tabular}{|c|c|c|}
\hline Principio de división del poder & $\begin{array}{c}\text { Principio de separación } \\
\text { entre poderes }\end{array}$ & $\begin{array}{l}\text { Principio de equilibrio entre } \\
\text { poderes }\end{array}$ \\
\hline $\begin{array}{l}\text { Sostiene la conveniencia de un ejercicio di- } \\
\text { vidido del poder político atendiendo a cri- } \\
\text { terios funcionales, siendo los más aceptados } \\
\text { los que distinguen entre las funciones legis- } \\
\text { lativas, ejecutivas y judiciales. }\end{array}$ & $\begin{array}{l}\text { Parte de la conveniencia no solo de } \\
\text { dividir funcionalmente el ejercicio del } \\
\text { poder, sino también el de separarlo física } \\
\text { y espacialmente como estrategia para } \\
\text { evitar su concentración y abuso. }\end{array}$ & $\begin{array}{l}\text { Acepta la conveniencia de los principios an- } \\
\text { teriores, pero agrega que deben establecer- } \\
\text { se controles interorgánicos que permitan la } \\
\text { concurrencia de ciertos poderes en funcio- } \\
\text { nes que son propias de otros para garantizar } \\
\text { su control efectivo y equilibrio recíproco. }\end{array}$ \\
\hline
\end{tabular}

Fuente: elaboración propia.

La teoría del Estado y la teoría constitucional de finales del siglo XIX y hasta mediados del siglo XX se ocuparon de examinar estos principios, a veces de manera superficial como en Heller (1997) o muy profunda como en Carré de Malberg (1998). Al revisar los autores clásicos de estas teorías se observa que ellos no hacen un esfuerzo juicioso por establecer la distinción que aquí se ha hecho, incluso, por el contrario, con frecuencia utilizan los términos de manera poco rigurosa, a veces como sinónimos. Sin embargo, tener estos principios claros hace que la distinción de poderes encaje en estas diversas formas de manifestación.

Sus consideraciones han girado alrededor de puntos como los siguientes: (i) si es posible o no dividir el poder del Estado - con lo cual puede desconocerse su soberanía o disiparse la unidad-, pues autores como Jellinek (2002) y Rousseau (1984) lo niegan, mientras que Friedrich (1946) no lo rechaza, aunque en general los teóricos del Estado prefieren hablar de división de funciones o competencias; (ii) si la separación de poderes, en general, protege o no la libertad de los ciudadanos, pues autores como Hauriou (1971) o Loewenstein (1976) lo aceptan, mientras que Duguit (1996) y Kelsen (1975) lo rechazan, aunque por razones muy diferentes; (iii) también, si es posible la igualdad y coordinación de órganos como lo defienden casi todos, o si es imposible, como ya se vio que lo sostiene Kelsen (1975).

\section{Las reivindicaciones contemporáneas de las premisas de la distinción de poderes}

Los términos "moderno" y contemporáneo" son usados en este artículo en un sentido 
débil, pues con el primero se busca designar el periodo que va entre el final del Medioevo europeo y el inicio de la contemporaneidad que es ubicada más o menos desde los años ochenta del siglo XX hasta hoy. La modernidad entonces haría referencia al proceso de configuración de los Estados europeos centrales, que pasarían del Estado absoluto al Estado nación, y también a la aparición del individuo, a la construcción de los derechos de libertad e igualdad, entre otras cosas; mientras que la contemporaneidad, o incluso, posmodernidad, haría referencia a la entrada en crisis de los Estados nación después de la Segunda Guerra Mundial, a la crisis del Estado de bienestar, la instauración del neoliberalismo, el surgimiento y extensión de los derechos colectivos y en general la globalización, todo ello hasta nuestros días (Montoya \& Vásquez, 2003).

Si bien ya se ha establecido que la doctrina de la separación de poderes tuvo su origen con el advenimiento de la modernidad política y dentro de un contexto caracterizado por el nacimiento del Estado liberal moderno, su difusión y adopción claramente trascendió esta coyuntura. Desde entonces hasta nuestros días, esta doctrina ha sido responsable de la forma en que se ha estructurado institucionalmente el poder político a nivel mundial, tanto desde una perspectiva teórica como práctica. Precisamente, ha sido a la luz del principio de la distinción de poderes y de sus distintos "entendimientos" desde el que se han construido las formas de gobierno predominantes en los Estados contemporáneos (García, 2000, p. 49).

En este orden de ideas, muchas de las premisas originarias anteriormente referidas mantienen su vigencia en el pensamiento político contemporáneo. A este respecto, resulta reveladora la definición que hace unos años proponía Vile (1998) de lo que él denomina la "doctrina pura" de la separación de poderes. En palabras del profesor norteamericano:

Es esencial para el establecimiento y mantenimiento de la libertad política que el gobierno esté dividido en tres ramas u órganos, el legislativo, ejecutivo y judicial. Para cada una de estas tres ramas les corresponde una función identificable de gobierno. Cada rama del poder debe estar confinada para el ejercicio de su propia función y no permitir que sus funciones se concentren en otras ramas. Además, las personas que componen estos tres órganos deben mantenerse separadas y distinguibles, a ningún individuo puede permitírsele que al mismo tiempo sea miembro de una o más ramas y órganos. De esta manera, cada una de las ramas será un freno para las demás y ningún grupo de personas estaría en capacidad de controlar la maquinaria del Estado (p. 14).

En este sentido, señala el autor que son tres los elementos que cimientan esta doctrina en el pensamiento contemporáneo. El primero es que los órganos del gobierno deben dividirse en tres categorías: la legislativa, la ejecutiva y la judicial; segundo, que existen tres funciones específicas del gobierno atribuibles a cada una de las categorías anteriores; y tercero, que las tres ramas del poder deben estar compuestas por personas separadas y distintas, sin solapamientos entre ellas (Vile, 1998, p. 16). Como puede evidenciarse, muchas de estas premisas retoman principios que fueron propuestos y aducidos en la modernidad por los fundadores de la misma y que, como se observa, mantienen plena validez en la realidad contemporánea.

De manera similar, Christoph Möllers (2013) recurre al concepto de libertad para defender desde una perspectiva normativa y conceptual la vigencia de la tridivisión clásica de los poderes. Para Möllers, la función principal que debe cumplir la distinción de poderes en el Estado contemporáneo radica en brindar mecanismos procedimentales que sirvan para solucionar conflictos entre el ejercicio de la libertad entendida como autodeterminación, tanto individual como colectiva, garantizando el equilibrio e igual reconocimiento entre ellas (p. 109). En una línea argumentativa análoga, las corrientes contemporáneas del garantismo suelen defender igualmente la vigencia de la 
distinción de poderes. Para ello se afirma que en el Estado los poderes deben estar separados y ser recíprocamente independientes como garantía de "la esfera de lo indecidible", es decir, de aquello sobre lo que no puede ser decidido por la mayoría, sino que corresponde al ejercicio de los derechos fundamentales (Ferrajoli, 2008, p. 341).

Desde las consideraciones kelsenianas (Kelsen, 1975) podría criticarse estas afirmaciones garantistas en un doble sentido: en primer lugar, porque la mera división no puede garantizar la libertad (p. 336), en razón de que persiste el hecho irreducible de que el legislador, incluso bajo controles, puede expedir normas jurídicas que la pongan en riesgo, dado que inexorablemente sus normas de carácter general, abstracto e impersonal son jerárquicamente superiores, y más allá de Kelsen, podría afirmarse algo similar si los tribunales constitucionales actúan de manera autoritaria; en segundo lugar, porque la libertad depende más de la representación diversa dentro de los órganos, especialmente dentro del legislativo, que de las divisiones orgánicas, que son imposibles en virtud de la imprescindible cooperación entre órganos para cumplir con los fines del Estado, o dicho en términos del austriaco, lo que existe es el reparto de una función entre varios órganos (p. 336).

Sin embargo, no es solo a partir de los argumentos clásicos del liberalismo desde donde suele defenderse la conveniencia de la distinción de poderes, sino que a raíz del particular auge que se tuvo en la reestructuración de los Estados afectados por la Segunda Guerra Mundial, se han formulado nuevos argumentos que han servido para mantener la vigencia y relevancia de esta doctrina constitucional. Así, Cass Sunstein (2001) sostiene que el sistema de distinción de poderes limita al poder haciendo más difícil para el gobierno actuar, pero al hacerlo, ayuda a empoderarlo y hacerlo más efectivo al crear una sana división del trabajo en su interior (p. 98). Por otra parte, considera el autor que la preservación de poderes y contrapoderes dentro del andamiaje estatal contribuye significativamente a que exista disidencia sobre los asuntos públicos a decidirse. En su razonamiento, la disidencia guarda una fuerte relación con la deliberación, la creatividad y creación de aprendizajes colectivos. En este sentido, señala Sunstein (2005) que "toda autoridad podrá cumplir mejor su función si ellos se enfrentan permanentemente a diversos puntos de vista y se exponen ellos mismos a un rango amplio de opiniones sobre los asuntos a decidir" (p. 68), situación que se facilita cuando se dispone de la existencia de un gobierno dividido, separado y controlado mutuamente.

Por lo tanto, de forma correlativa, señala el autor norteamericano que la existencia de controles recíprocos entre los poderes públicos ha evitado el abuso de poder, el faccionalismo y la imposición de una única concepción de vida buena y, por el contrario, ha estimulado y protegido la disidencia el desarrollo de una democracia deliberativa (Sunstein, 2005, p. 158). Un tercer argumento sostenido por el autor para defender la conveniencia del principio de separación de poderes afirma que este arreglo institucional aumenta los puntos de acceso al gobierno, permitiendo que las demandas de los ciudadanos puedan acceder a alguna de las otras ramas del poder cuando han sido bloqueadas por otra (p. 99).

Por su parte, Stephen Holmes (1995) destaca la potencia creativa de la separación de poderes al advertir que dicho arreglo institucional enriquece el proceso de toma de decisiones, en tanto los distintos actores del sistema, en efecto, se ven obligados a anticipar las posibles objeciones de los demás jugadores modificando de antemano sus propuestas iniciales e introduciendo variables destinadas a contemplar los restantes intereses en juego (p. 164). En este razonamiento, cada uno se encuentra forzado a pensar en los demás, a encontrar en sus iniciativas aspectos que puedan servir al resto de la sociedad, y con ello se favorece e incentiva la deliberación 
social y así, un proceso colectivo de creación normativa (p. 271).

Posteriormente, George Tsebelis (2002) ha defendido la vigencia de la doctrina de la separación de poderes al advertir que este modelo aumenta la estabilidad política. Si bien el autor parte de no comprometerse con un concepto valorativo de lo que él denomina como "estabilidad política", con su teoría de los actores con poder de veto (veto players), a saber, una institución que es propia del principio de frenos y contrapesos, comprueba empíricamente que a la mayor existencia de dichos actores en el sistema será más complejo cambiar el statu quo existente y, por ende, el sistema será más proclive a cambios moderados y progresivos. En los estudios del autor, los actores con poder de veto no solo serán aquellos expresamente previstos por el sistema constitucional, como los relacionados con el veto presidencial o judicial a las leyes promulgadas por el órgano legislativo, sino también otros actores como la burocracia en el interior de las ramas del poder. Por lo tanto, de la teoría desarrollada puede concluirse que si lo pretendido por los arreglos institucionales incluye la durabilidad y la estabilidad de un régimen político como un fin deseable, una de las variables fundamentales para ello será tener en cuenta el número y poderes de los actores con veto dentro del sistema político. Un argumento similar puede rastrearse en la obra La quiebra de las democracias, del profesor Juan Linz (1996), en donde se prueba el fuerte nexo que existe entre la independencia de ciertas instituciones y la estabilidad de las democracias contemporáneas.

Y más recientemente, Jeremy Waldron (2013), ha afirmado que la doctrina de la distinción de poderes guarda una significativa relevancia aún hasta nuestros días a partir de la gobernabilidad articulada (articulated governance) que construye (p. 455). Para ello, el profesor norteamericano parte de considerar que este principio toma el proceso de gobierno y lo divide conceptualmente entre las tres funciones ya conocidas, a saber, en la creación de la ley, su administración y la adjudicación de derechos con base en ella. De esta conceptualización, se derivan dos premisas: por un lado, que es un error pensar que el ejercicio del poder político es algo simple; y por otro, que cada fase en la cual está dividido el ejercicio del poder es importante en sí misma $\mathrm{y}$ que por su particularidad deben ser atendidos por cada una de las ramas. A partir de ambas premisas, señala el profesor norteamericano que este arreglo institucional conduce a que la acción gubernamental debe estar articulada a través de una sucesión de fases diferentes una de otra, ya que el que así sea, es una garantía para la vigencia del derecho, el debido proceso, la libertad política y la dignidad, incluso de las decisiones mayoritarias (p. 458).

\section{El "gobierno administrativo" $y$ el déficit democrático de la distinción de poderes}

Como ya se expuso, la doctrina de la distinción de poderes sigue gozando de defensores contemporáneos que abogan por su permanencia, ello no obsta para que de igual forma existan también fuertes detractores de esta doctrina y aboguen por su revisión y actualización ante los retos que enfrentan los Estados contemporáneos. En este sentido, podemos identificar dos grandes líneas hacia las cuales se orientan las críticas que se hacen actualmente a la distinción de poderes: de una parte, encontramos las críticas que se formulan por su falta de eficiencia frente a las funciones que hoy en día se le atribuyen al Estado; y de otra, el déficit democrático que implica.

Frente a la primera línea de las críticas, se parte de considerar que la distinción de poderes responde a una doctrina típicamente circunscrita al nacimiento del Estado liberal moderno como un instrumento para garantizar el control del poder político. En este sentido, con el advenimiento del constitucionalismo 
social a comienzos del siglo XX, y en especial, tras su consolidación durante la época de la segunda posguerra, el Estado adquirió toda una serie de funciones prestacionales claramente distinguibles de típicas funciones abstencionistas propias de un Estado liberal clásico (Bobbio, 1990, pp. 371-394). Por lo tanto, la legitimidad del Estado ya no puede encontrarse únicamente en el sometimiento que este haga a los derechos de libertad negativa de los ciudadanos, sino que comenzará a ser evaluada por el efectivo cumplimiento de los derechos prestacionales, a saber, sociales, económicos, culturales, e incluso colectivos (Del Aguila, 2004, p. 599).

Este cambio de paradigma estatal ha hecho que la escala y la complejidad de los gobiernos contemporáneos hayan aumentado haciendo que algunas de sus funciones ya no puedan ser categorizadas como legislativas, ejecutivas o judiciales exclusivamente (Ackerman, 2010, p. 129). Si bien inicialmente para responder a estas nuevas demandas se consolidó la necesidad de crear grandes burocracias gubernamentales encargadas de la prestación de estos nuevos servicios, los problemas asociados a ellas, a saber, sus ineficiencias, alto costo fiscal, paquidermia institucional, exceso de formalismos, entre otras, hicieron que a finales del siglo XX se replanteara el esquema general y se reafirmara la necesidad de reducir el tamaño de las entidades estatales a raíz de las restricciones presupuestales existentes, inspiradas en reestructuraciones derivadas de ciertos cambios económicos y acuerdos posteriores como el Consenso de Washington. En este orden de ideas, en la actualidad vivimos una coyuntura dialéctica caracterizada por unas restricciones fiscales relevantes, pero a su vez por unas expectativas cada vez mayores por parte de los ciudadanos frente al Estado en relación con el cumplimiento efectivo de sus derechos constitucionales, las cuales además han dado lugar a importantes tensiones entre los órganos que ejercen las funciones legislativa, ejecutiva y judicial. Esta nueva realidad, ha llevado a que se realicen significativos cambios al modelo de administración de lo público, caracterizado por la implementación de privatizaciones, promoción de la competencia en la prestación de los servicios públicos y el uso prevalente de técnicas regulatorias por parte de los Estados (Loughlin, 2010, p. 447).

Este nuevo esquema público-administrativo ha traído como principal consecuencia el que no solo se cambien los roles entre el sector público y privado, sino que los límites entre ambos se hayan hecho cada vez más borrosos. Un típico ejemplo de ello lo constituye el auge de los no-elegidos (The Rise of the Unelected), como lo ha denominado recientemente Frank Vibert (2007) para referirse a ese conjunto de nuevas agencias que a pesar de que sus miembros no han sido electos directamente, y que incluso se afirman independientes de los típicos poderes públicos $\mathrm{y}$, por ende, no responden a un mandato democrático, cada vez desarrollan más claramente funciones ejecutivas, judiciales e incluso legislativas (p. 7). Incluso, hoy en día, la gran generalidad de asuntos que se refieren a las realidades más cercanas a los ciudadanos contemporáneos, como la calidad de sus servicios públicos, los procedimientos para acceder a bienes y servicios, los ajustes macroeconómicos, entre muchos otros aspectos, son decididos actualmente por estas agencias independientes.

Todo este nuevo cambio en el andamiaje mismo del Estado contemporáneo, al que suele hacerse referencia como Estado Administrativo (Administrative government) ha servido para que se replantee la vigencia y la conveniencia de la doctrina de la distinción de poderes como estructuradora del actual poder estatal. En este sentido, Rosenbloom (1983) ha señalado con contundencia que:

Este modelo de gobierno [a partir de la separación de poderes] no ha sido visto como el más adecuado para la implementación de políticas públicas dirigidas a una amplia intervención en las condiciones económicas y so- 
ciales de la comunidad política. Este modelo está balanceado hacia la inercia, inflexibilidad y descoordinación (p. 34).

Por lo tanto, afirma el autor que el andamiaje institucional que se deriva de la distinción o separación de poderes resulta anacrónico e inadecuado para desarrollar las funciones que el Estado Administrativo requiere hoy en día.

Más recientemente, estas críticas se han exacerbado, en especial por un influyente texto escrito por Eric Posner y Adrian Vermeule (2011). Para estos profesores norteamericanos, su punto de partida es que actualmente se vive bajo un Estado Administrativo que provee toda clase de bienes sociales, lo cual ha contribuido a una clara acumulación de poder por parte de agencias ejecutivas (p. 54). Lo anterior ha ocurrido a pesar de la existencia formal de la separación de poderes, lo cual les permite afirmar que lo así dispuesto por la Constitución no corresponde más a la realidad, en tanto, el Congreso ha asumido un rol secundario al ejecutivo y el poder judicial cumple un rol simplemente marginal. En este sentido, para los autores, la distinción de poderes es un principio constitucional anacrónico y obsoleto que ha sido reemplazado materialmente por parte de la opinión pública y la política partidista como únicos controles al poder ejecutivo exacerbado (p. 162).

Por otra parte, existe una segunda línea de críticas contemporáneas a la distinción de poderes, la cual se centra en el déficit democrático que se deriva del mismo. Si bien esta línea crítica puede remontarse desde las discusiones que dieron origen a la Constitución norteamericana (Vile, 1998, p. 230), en la actualidad esta ha sido reivindicada por la corriente del pensamiento político Republicano y por aquellos que defienden una noción "fuerte de democracia". En este sentido, Richard Bellamy (2007) identifica al menos tres problemas en la doctrina de la separación de poderes ante los retos del Estado contemporáneo (p. 201). En primer lugar, se ha vuelto cada vez más completa, tanto teórica como prácticamente, una distinción clara a las diferentes funciones que actualmente desarrolla el Estado. En este punto, aspectos como el que los jueces puedan crear derecho a través de precedentes judiciales o los reglamentos expedidos por el ejecutivo tengan alcances propios de actos legislativos, no permite afirmar que cada una de las tres ramas actuales están comprometidas unas con otras, lo cual se intensifica ante la complejidad crecientes del gobierno contemporáneo. De igual forma, el común reconocimiento de la existencia de otras "ramas del poder público", como los medios de comunicación o las agencias independientes, prueban igualmente estas dificultades (Loughlin, 2010, p. 448). Más específicamente, incluso, la tendencia creciente a que los particulares cumplan funciones administrativas (Suárez, 2012).

Un segundo problema identificado es que suponiendo que dicha distinción funcional fuera posible esta no necesariamente ha contribuido al freno de poderes arbitrarios. Para ello señala el autor que la tesis original que preveía que si dichas funciones pudieran ser desarrolladas por diferentes sectores sociales se lograrían controlar, ha sido rebatida por la práctica contemporánea. En este sentido, si las distintas ramas del poder público son ocupadas por grupos políticos diferentes son claros los efectos de bloqueo, inacción e ineficiencias del Estado en sus funciones debido a la inexistencia de incentivos institucionales para actuar de otra manera. Por el otro lado, si los poderes públicos están compuestos mayoritariamente por un mismo grupo político, situación que la realidad nos ha mostrado como común, el modelo de distinción de poderes se muestra claramente incapaz de brindar un control efectivo al ejercicio del poder público (Bellamy, 2007, p. 202).

El tercer y más relevante problema para el autor, se refiere a que la separación de poderes falla en proveer incentivos que aseguren el que sus agentes sirvan a los intereses de los 
ciudadanos. Para desarrollar esta crítica señala que la doctrina de separación de poderes responde a la lógica exclusiva de un control horizontal al ejercicio del poder, sin embargo, carece de cualquier instrumento de control vertical del mismo donde los ciudadanos puedan buscar la responsabilidad política (accountability) de los que ejercen el poder. En este sentido, no existe en esta doctrina una garantía para que los intereses de los ciudadanos coincidan con los intereses de los funcionarios nombrados, propiciando, como lo ha probado la práctica, que dicha clase política ejerza sus funciones en beneficio de intereses propios.

Este argumento ha sido igualmente desarrollado por Gargarella (2003) para quien esta falta de controles verticales en la distinción de poderes sumada a un modelo de democracia representativa que tiende de manera deliberada a alejar cada vez más a los representantes de los ciudadanos, ha dejado en evidencia los déficits del sistema de un gobierno equilibrado. En este sentido, afirma el autor:

Nuestro sistema institucional fue fundado a partir de presupuestos muy discutibles: una sociología política inadecuada, que generó la ilusión de que el sistema institucional podría "dar cabida" a toda la sociedad asegurando, a la vez, una protección especial para sus miembros más débiles; discutibles presupuestos epistémicos que vinieron a justificar una drástica separación entre representantes y representados; y una poco atractiva concepción de la democracia, que no sólo tendía a dejar de lado toda preocupación seria sobre el papel de la voluntad mayoritaria, sino que daba pie para la creación de una muy objetable estructura de incentivos institucionales (p. 22).

Por lo tanto, se viene a afirmar por parte de esta posición que la doctrina de la distinción de poderes, sumada a una versión "débil" de democracia representativa, ha contribuido a que tenga lugar un patológico pero previsible alejamiento entre los representantes que desempeñan cargos en los órganos del Estado y los ciudadanos, $y$, por ende, se ha contribuido a una peligrosa pérdida de confianza entre la institucionalidad política y los ciudadanos. De allí que sea necesario repensar el valor democrático que tiene la doctrina de la distinción de poderes en nuestros días.

\section{Conclusiones}

A manera de conclusión, puede señalarse que, al rastrear los orígenes de la doctrina de la distinción de poderes, si bien puede remontarse a la antigüedad, serán postulados típicamente modernos los que configuren las premisas de la doctrina como suele utilizarse hoy en día. De allí que, al revisar nuevamente los razonamientos propuestos en la obra de Locke, Montesquieu, Madison, Hamilton y Jay, podemos afirmar que cada uno de ellos teorizó sobre principios que bien pueden distinguirse a pesar de que contemporáneamente compongan la doctrina de la distinción de poderes.

En este sentido, en la obra de Locke evidenciamos cómo se materializa allí la empresa que había comenzado desde la antigüedad de intentar distinguir entre las funciones que deben ser desarrolladas por el poder político. Por su parte, en los escritos de Montesquieu, constatamos una argumentación tendiente a procurar la separación física de quienes ejerzan las distintas funciones estatales como estrategia para evitar la concentración y el abuso del poder político. Por último, en Madison, encontramos cómo el modelo del gobierno dividido y separado debía complementarse a través del establecimiento de frenos y contrapesos que sirvieran de controles recíprocos para equilibrar el ejercicio del poder político a través del cumplimiento de sus funciones ordinarias compartidas. Por lo tanto, desde la modernidad hasta nuestros días, con la distinción de poderes suele hacerse referencia conjunta a los principios de división del poder, separación entre poderes y equilibrio entre poderes.

Desde su formulación moderna, esta doctrina no solo ha gozado de una gran influencia 
en la estructuración del poder político desde entonces, sino que también contemporáneamente se encuentran fuertes defensores de su vigencia y conveniencia frente a los retos que enfrenta el Estado contemporáneo. Así, se encuentran argumentos que sostienen que la existencia de instituciones políticas divididas, separadas y controladas mutuamente sirve para asegurar la estabilidad de la democracia, fomenta el sano disentimiento y la deliberación, aumenta los puntos de acceso de los individuos al poder y favorece una gobernabilidad articulada que garantiza los derechos individuales.

Sin embargo, como es igualmente previsible, otro grupo de autores contemporáneos se ha dado a la tarea de reevaluar la conveniencia y vigencia de la distinción de poderes frente a los retos que enfrenta el Estado contemporáneo. En este sentido, pueden evidenciarse dos líneas críticas. Por un lado, se encuentra aquella que parte de considerar que por la complejidad que implica el gobierno administrativo contemporáneo, la distinción de poderes no solo ya no opera debido a la emergencia de nuevas funciones que escapan a la tradicional redivisión de poder, como lo son las agencias independientes, sino también porque esta doctrina genera ineficiencias que hacen que no sea la estructura más adecuada para la nueva administración de lo público que requiere el Estado en la actualidad.

Por otro lado, encontramos una serie de críticas que advierte el déficit democrático que implica la doctrina, el cual, sumado a un modelo de democracia representativa, ha venido a crear un distanciamiento dramático entre los representantes en los poderes públicos y los ciudadanos. Este fenómeno ha generado que con mayor relevancia se pierda la relación de confianza de los ciudadanos en las instituciones públicas $\mathrm{y}$, por ende, se haya dado lugar a revaluar la relevancia de la democracia en los Estados contemporáneos.

A manera de balance, puede señalarse que, como pudo evidenciarse en el estado actual del arte, la pregunta sobre la vigencia y conveniencia de la distinción de poderes como la doctrina responsable de la estructura del Estado contemporáneo es un asunto de absoluta actualidad y conveniencia. Interesantes argumentos han sido propuestos por defensores y detractores del mismo. Tal vez para una mejor comprensión y evaluación de los mismos resulte conveniente como un ejercicio futuro, el sistematizar dichos argumentos atendiendo a sus fundamentos, a saber, teóricos o empíricos, y a los principios o premisas que dentro de la doctrina de distinción de poder se dirigen, tal y como se distinguió en el apartado primero de este escrito. Este ejercicio, sin lugar a dudas, puede brindarnos nuevas herramientas para avanzar en esta trascendental discusión para el devenir del Estado contemporáneo.

Por último, no debe perderse de vista que del rastreo realizado, puede afirmarse que la doctrina de la distinción de poderes ha estado y está comprometida con la libertad política como una parte esencial de los límites del poder político; por lo tanto, lo que está en juego con la vigencia o no de la misma no es otro asunto que la aspiración humana que ha trascendido por siglos y que propende por un sistema de gobierno en el cual el ejercicio del poder político esté limitado y sometido a control. Por consiguiente, es una discusión que deberá abordarse con la mayor responsabilidad política y moral. Conviene entonces terminar con la observación de Friedrich (1946), quien admite que si bien la división de poderes tiene problemas, es importante tomar en cuenta que su concentración siempre será peor (p. 186).

\section{Referencias}

Ackerman, B. (2010). Good-bye, Montesquieu. En S. Rose-Ackerman \& P. L. Lindseth (Eds.), Comparative Administrative Law: Research Handbook in Comparative Law series (pp. 128-133). Cheltenham, Reino Unido: Edward Elgar Pub.

Aristóteles. (2001). La Política. Barcelona: Folio. 
Bellamy, R. (2007). Political Constitutionalism: A republican Defense of the Constitutionality of Democracy. Nueva York: Cambridge University Press.

Bobbio, N. (1990). Contribución a la teoría del derecho. Madrid: Debate.

Bolingbroke, H. (1997). Political Writings. Cambridge: Cambridge University Press.

Carré de Malberg, R. (1998). Teoría General del Estado. México: Fondo de Cultura Económica.

Asamblea Constituyente francesa. (1789). Declaración de los Derechos del Hombre y del Ciudadano. Francia

Del Aguila, R. (2001). El centauro transmoderno: liberalismo y democracia en la democracia liberal. En F. Vallespin (Ed.), Historia de la teoría Política (Vol. 6, pp. 529-618). Madrid: Alianza Editorial.

Duguit, L. (1996). La separación de poderes y la Asamblea Nacional de 1789. Madrid: Centro de Estudios Constitucionales.

Ferrajoli, L. (2008). La esfera de lo indecidible y la división de poderes. Estudios Constitucionales, 6(1), 337-343.

Friedrich, C. (1946). Teoría y realidad de la organización constitucional democrática. México: Fondo de Cultura Económica.

García, J. (2000). Del principio de la división de poderes. Revista de Estudios Políticos, 108, 41-75.

Gargarella, R. (2003). Sobre los déficits del sistema de "Frenos y Contrapesos". Rosario: Conicet.

Guastini, R. (2000). Estudios de teoría Constitucional. México: Universidad Nacional Autónoma de México.
Harrington, J. (1999). The Commonwealth of Oceana and A System of Politics. Nueva York: Cambridge University Press.

Hauriou, A. (1971). Derecho constitucional e instituciones políticas. Barcelona: Ediciones Ariel.

Heller, H. (1997). Teoría del Estado. México: Fondo de Cultura Económica.

Holmes, S. (1995). Passions \& Constraint. On the Theory of Liberal Democracy. Chicago: The University of Chicago Press.

Jellinek, G. (2002). Teoría General del Estado. México: Fondo de Cultura Económica.

Kelsen, H. (1975). Teoría General del Estado. México: Editora Nacional.

Linz, J. (1996). La quiebra de las democracias. Madrid: Alianza.

Locke, J. (1959). Segundo Tratado sobre el Gobierno Civil. Buenos Aires: Ágora.

Loewenstein, K. (1976). Teoría de la Constitución. Barcelona: Editorial Ariel.

Loughlin, M. (2010). Foundation of Public Law. Nueva York: Oxford University Press.

Madison, J., Hamilton, A., \& Jay, J. (2010). El federalista ( $2^{\mathrm{a}}$ ed.). México D. F.: Fondo de Cultura Económica.

Marsilio de Padua. (2009). El defensor de la paz. Madrid: Tecnos.

Montesquieu. (1977). El espiritu de las leyes. México: Porrúa.

Montoya, M., \& Vásquez, A. (2013). Hacia un panorama teórico de las afecciones y 
riesgos colectivos en Colombia. Estudios de Derecho, 61(137), 15-27.

Möllers, C. (2013). The Three Branches: A comparative Model of Separation of Powers. Oxford. Oxford: University Press.

Neustadt, R. E. (1990). Presidential Power and the modern presidents. Washington D.C: Free Pr.

Polibio. (2008). Historia de Roma. Madrid: Alianza.

Posner, E., \& Vermeule, A. (2011). The executive unbound: after the madisonian republic. Nueva York: Oxford University Press.

Rosenbloom, D. H. (1983). Public administrative theory and the separation of powers. Public Administrative Review, 43(3), 219-227.

Rousseau, J. (1984). El contrato social. Madrid: Sarpe.

Rubin, E. L. (2005). Beyond Camelot: Rethinking Politics and law for the Modern State. Nueva Jersey: Princeton University Press.
Schmitt, C. (2011). Teoría de la Constitución. Madrid: Alianza Editorial.

Suárez, D. (2012). Particulares que ejercen funciones administrativas: el caso de los tribunales de ética profesional. Opinión Jurídica, 11(21), 39-56.

Sunstein, C. (2001). Designing Democracy: What Constitutions Do?. Nueva York: Oxford University Press.

Sunstein, C.(2005). Why societies need dissent? New Heaven: Harvard University Press.

Tsebelis, G. (2002). Veto Players: How Political Institutions Works. Nueva Jersey: Princeton University Press.

Vibert, F. (2007). The Rise of the Unelected: Democracy and the New Separation of Powers. Nueva York: Cambridge University Press.

Vile, M.(1998). Constitutionalismandseparation of powers. Indianápolis: Liberty Fund.

Waldron, J. (2013). Separation of Powers in Thought and Practice? Boston College Law Review, 54, 433-468. 
